\title{
Mudanças Percebidas nas Relações de Amizade por Mulheres de Meia-idade Cursando a Universidade
}

\author{
Sandra Bomfim Leonel \\ Universidade Federal do Espírito Santo \\ Agnaldo Garcia ${ }^{2}$ \\ Universidade Federal do Espírito Santo
}

\begin{abstract}
RESUMO
A pesquisa investigou as mudanças percebidas nas amizades por mulheres de meia-idade após sua inserção em uma universidade. Buscaram-se as mudanças percebidas no relacionamento com amigos antigos e o estabelecimento de novas amizades dentro da universidade. Participaram da pesquisa oito graduandas de 40 a 60 anos, que responderam a uma entrevista semiestruturada, cujos dados foram submetidos a análise de conteúdo. Foram elaboradas cinco categorias: relacionamento interpessoal na universidade, construção e propriedades das novas amizades, atividades com os novos amigos, distinção entre amizades antigas e recentes, e mudanças na rotina com amigos antigos. Conclui-se que as amizades sofreram mudanças com a entrada na universidade.
\end{abstract}

Palavras-chave: Meia-idade; mulheres; amizade; universidades.

\begin{abstract}
Perceived Changes in Friendship Relations By Middle Aged Women Studying at University

The research has investigated middle aged women and the changes in their friendships after joining a university. It was observed changes in old friendships, and also the establishment of new ones at the university. The research was based on eight women, between 40 and 60 years old, who had been subjected to a semi structured interview. The data were subjected to content analysis and the results were organized in five categories: interpersonal relationship at the university, development and characteristics of new friendships, activities involving new friends, differences between new and old friendships, and routine changes in old friendships. The final results show that, after participants got into university, all friendships suffered modification.
\end{abstract}

Keywords: middle aged; women; friendship; colleges.

$\mathrm{Na}$ atualidade, novos horizontes se abrem para uma mulher mais esclarecida e livre para fazer escolhas, buscar outros espaços e assumir uma diversidade de papéis inadmissíveis até pouco tempo atrás. De acordo com Giolo e Ristoff (2006), em 2004 havia 27.300 mulheres, $55 \%$ do total de pessoas com idade entre 40 e 60 anos, matriculadas em uma graduação na região Sudeste do país. Estima-se que, 11 anos depois, esse número de universitárias na meia-idade tenha crescido consideravelmente. O censo de 2010 aponta um número expressivo de mulheres com idade superior a 40 anos cursando uma graduação: $35 \%$ do total da população feminina, segundo dados do Instituto Brasileiro de Geografia e Estatística (IBGE) (2011). A retomada dos estudos na maturidade da à mulher recursos para acompanhar as mudanças e as novas exigências sociais.

\section{A mulher de meia-idade e a mulher na universidade}

Em relação à mulher de meia-idade, a literatura psicológica ainda é escassa. Uma busca na SciELO sobre meia-idade resultou em apenas 27 publicações de 2007 a 2014. Vários desses artigos tratavam de questões de saúde da mulher de meia-idade (e.g. Guimarães \& Baptista, 2013). Entre estudos publicados em revistas de Psicologia, está um sobre o significado da morte para adolescentes, adultos e idosos, que registra a participação de mulheres de meia-idade. A população feminina na meia idade foi a que mostrou maior angustia e ansiedade ao falar da morte (Barbosa, Melchiori \& Neme, 2011).

No âmbito do trabalho, Leão e Gíglio (2002) investigaram a psicodinâmica da mulher trabalhadora 
de meia-idade em fase de pré-aposentadoria. Segundo os autores, a meia-idade é uma faixa etária bastante relevante para pesquisas, principalmente em relação às mulheres, pelas atuais exigências ambientais, desejo de progresso, integração e produtividade social.

Alguns artigos que discutem a mulher de meia-idade não se referem à sua relação com a universidade. Marcelja (2012), por exemplo, analisou o conteúdo de uma revista voltada para a mulher de meia-idade. Entre os temas abordados estavam beleza e saúde, moda e estilo, leitura e lazer, casa e cozinha, corpo e mente. Ferreira (2008), ao tratar das relações entre a meiaidade e a alta modernidade entrevistou algumas mulheres nessa faixa etária. Quatro dessas mulheres, que já estavam com seus filhos crescidos, sendo que três delas também estavam aposentadas, procuraram a universidade para ocupar de forma prazerosa o tempo. Segundo a autora, uma delas havia voltado aos estudos após passar por um período de depressão.

Para Papalia e Olds (2000) os anos intermediários ou meia-idade têm um conteúdo que varia bastante, dependendo do contexto sociocultural de quem os vivencia. Aos 40 anos, algumas mulheres tornam-se mães pela primeira vez, enquanto outras se tornam avós. Aos 50 anos, algumas mulheres estão iniciando novas carreiras, enquanto outras estão aposentando-se. Esse tema é descrito como um conceito socialmente construído e imposto dentro das variadas formas culturais, visto que em algumas sociedades não se reconhece essa etapa como uma fase diferenciada, com suas próprias normas, papéis e desafios.

Nessa etapa da vida, os prejuízos físicos e corporais são contrapostos ao ganho cognitivo e psicológico como possibilidade viável. Segundo Jorge (2005), os relacionamentos e os vínculos mudam na maturidade, tanto no sentido de um estreitamento das relações quanto no de um distanciamento do que não se aplica mais à sua vida. Observa-se a necessidade de mudança constante do indivíduo para se adaptar às transformações inabaláveis que ocorrem no ambiente.

Porém, os conflitos femininos nessa faixa etária tendem a crescer quando não se atendem as exigências do novo padrão de mulher valorizado, segundo Nogueira (2001). Esse atual modelo vem associado a novas formas de viver a maturidade. A mulher contemporânea, na meia-idade, se insere em um tempo em que coexistem o molde antigo e o modelo atual de mulher, que equilibra os arcaicos valores morais em que foi criada e as novas exigências impostas a ela nesse momento. Com isso, vai aos poucos buscando a sua transformação, inserindo-se em novos espaços, entre eles a universidade, transformando a si e a seu grupo relacional.

Uma busca na SciELO para o período de 2010 a 2014, relacionando mulher e universidade no Brasil e utilizando como palavras-chave mulher e universidade, sem restrição a idioma, indicou que esse é um tema recorrente na literatura, porém raramente sobre mulheres de meia-idade. Parte da literatura investiga a inserção da mulher na universidade, geralmente de um ponto de vista histórico (e.g. Baldissera, Grecca \& Santos, 2010; Reis \& Brito, 2012), sem, contudo destacar a mulher de meia-idade. Outras investigações tratam da mulher de meia-idade como profissional ligada à universidade (Merighi, Jesus, Domingos, Oliveira \& Baptista, 2011).

\section{Relacionamento interpessoal na universidade}

A literatura sobre amizade e universidade é extensa, especialmente no contexto internacional. Um levantamento amplo sobre amizade e universidade com base no PsycINFO, para o período entre 2010 e 2014, utilizando como palavras-chave amizade/friendship e universidade/university, revelou uma série de dezenas de artigos sobre relações inter-raciais (e.g. Kim, Park \& Koo, 2014; Bowman \& Park, 2014; Charles, 2012) ou então sobre amizade e a formação de redes sociais (e.g. Wang, Jackson, Gaskin, \& Wang, 2014).

No Brasil, as relações interpessoais no ambiente universitário ainda são pouco investigadas. A universidade se apresenta como um espaço de interação social e diversidade cultural, permitindo uma pluralidade de experiências de socialização que vão afetar a rede de relacionamentos dos estudantes. Conforme Nogueira (2001), as transformações nessas redes se dão de forma entrelaçada e num longo procedimento de construção da própria trajetória pessoal de desenvolvimento.

A entrada no ensino superior exige do indivíduo uma adequação emocional com a finalidade de elaborar uma nova rede de apoio social e de reavaliar os relacionamentos prexistentes em adultos jovens, segundo Rawlins (1992). Compreendendo a fase estudantil universitária como favorável à formação de grandes amizades, é importante considerar esse espaço como um contexto educacional que exerce papel significativo na caminhada escolar do adulto, marcando-o de forma cognitiva, emocional e social. 
Garcia e Brandão (2010) e Peron, Guimarães e Souza (2010) investigaram amizades no período universitário entre jovens adultos. Os dados mostraram a amizade como um relacionamento que envolve uma ampla gama de interações possíveis, mantendo relações dialéticas com essas interações e com grupos sociais. A amizade no período universitário, para esses estudantes, atenta para um desenvolvimento socioemocional.

Garcia e Leonel (2007), Webber e Celich (2007) e Irigaray e Schneider (2008) investigaram os idosos de universidades abertas para a terceira idade e concluíram que eles percebem uma melhoria significativa na sua qualidade de vida, com o desenvolvimento de novas relações interpessoais e implicações nas práticas voltadas para a integração e a socialização do idoso. Constataram contribuições na vida pessoal, nos relacionamentos com amigos/sociedade, no exercício de sua cidadania, assim como mostraram um novo sentido para a vida, a ocupação do tempo livre e o lazer. Esses autores concluíram que as universidades da terceira idade vêm contribuindo positivamente para o bem-estar de idosos. Simoneau e Oliveira (2011) analisaram a estrutura da representação social de um programa universitário para pessoas idosas a partir do olhar dos idosos. Observaram que eles apresentam uma representação muito positiva desses programas universitários, ressaltando sua função social ao propiciar o estabelecimento de laços de amizade, união, alegria, valorização do idoso e integração social.

Enquanto o papel da universidade nas relações interpessoais de jovens adultos e idosos tem sido investigado de forma relativamente extensa, há escassas referências à vida social de estudantes de meia-idade em nosso meio acadêmico. Toneloto (1998) propôs-se a mostrar as dificuldades e os desafios que as mulheres de meia-idade enfrentam ao cursar uma graduação. $\mathrm{O}$ estudo mostrou que a frequência à universidade traz uma ressignificação ao cotidiano dessas estudantes.

A qualidade de vida de homens e mulheres que ingressam na universidade após os 45 anos de idade foi investigada por Raposo (2006), que realizou um estudo sobre o tema: se ocorreram mudanças na vida desses estudantes, como se manifestaram e se são percebidas como melhoria na qualidade de vida. Segundo a autora, os resultados revelam que os respondentes, antes de ingressarem no ensino superior, vivenciaram um período sem inovações, estável e apresentaram melhorias na qualidade de vida após sua inserção no meio acadêmico.

\section{Relacionamentos de amizade entre adultos}

Considerada uma das mais comuns relações interpessoais que a maioria dos seres humanos apresenta, a amizade está permeada pelo apreço entre duas pessoas que se gostam, havendo reciprocidade e confiança entre elas (Garcia, 2005). Uma investigação de produções científicas sobre amizade em periódicos estrangeiros, feita por Souza e Garcia (2008), aponta a amizade concebida de forma distinta, da infância à velhice, por diversos pesquisadores. $\mathrm{Na}$ fase adulta jovem, as relações se intensificam dentro do contexto universitário (Rawlins, 1992).

Hutz e Souza (2008) também fazem uma revisão de literatura sobre as relações de amizade na vida adulta e o quão pouco essa área é provida de pesquisas. A partir dos estudos revisados, apontam que indivíduos socialmente integrados vivem mais e que os relacionamentos familiares e de amizade, assim como os românticos, amenizam a solidão e proporcionam um bem-estar subjetivo.

Para Nogueira (2001), a rede de amizades de adultos de meia-idade se apresenta menor que a de adultos jovens. Elas são centradas na família, o que parece próprio dessa etapa de vida. O estudo dessa autora apontou para uma rede social mais ampla para as mulheres que para os homens, devido aos papéis socioculturais atribuídos a ela. Sousa e CerqueiraSantos (2011), em artigo de revisão sobre redes sociais e amizades ao longo do ciclo vital, referem-se à diminuição do número de amigos na adultez intermediária, reduzindo-se a partir dos 30 anos. Eles sugerem que a adoção de diversos papéis na vida adulta poderia dificultar a formação de amizades. Segundo os autores, na adultez intermediária, o número total de amigos diminui em função de os adultos, inclusive de meia-idade, estarem bastante envolvidos em outros papéis, como pais, cônjuges e trabalhadores, e parcialmente porque tendem a se contentar com as amizades atuais. Não há, contudo, mais detalhes quanto às mulheres de meia-idade.

\section{Relacionamento interpessoal na visão de Robert Hinde}

A presente pesquisa tem como referencial teórico a obra de Robert Hinde, especialmente Hinde (1997), que representa uma importante contribuição para a investigação sobre relações interpessoais, por oferecer uma proposta de sistematização à pesquisa na área $\mathrm{e}$ inserir os relacionamentos em um contexto mais amplo. 
Hinde (1997) diferencia interação e relacionamento entre pessoas. Enquanto uma interação se refere a um encontro isolado entre duas pessoas, um relacionamento se desenvolve a partir de uma sequência de interações entre as pessoas, de modo que, nos relacionamentos, cada interação é afetada pelas precedentes e pela expectativa de futuras interações. Um conjunto de relacionamentos dará origem a um grupo social, de modo que interações, relacionamentos e grupos são vistos como diferentes níveis de complexidade da vida social. Esses diferentes níveis se afetam mutuamente e ainda afetam e são afetados de forma dialética ou recíproca pelo ambiente físico e pela estrutura sociocultural. Um sujeito, para ser compreendido, deve ser avaliado dentro do grupo e da rede de relações das quais participa.

Segundo Hinde (1997), entre os fatores que se encontram na base do relacionamento estão semelhanças e diferenças entre os seus integrantes. Nos relacionamentos, o conflito é uma característica que pode se apresentar de maneira positiva, quando existem compromisso e confiança entre seus membros, mas pode se mostrar também de forma destrutiva quando há um clima de ameaça entre os parceiros. O poder é outra propriedade do relacionamento, que vai depender da influência que uns têm sobre os outros, modificando, assim, o comportamento do parceiro. A autorrevelação e a privacidade também estão presentes nas interações e podem afetar a qualidade do relacionamento.

Outros aspectos destacados por Hinde (1997) incluem a percepção interpessoal, que inclui a percepção de si mesmo, do parceiro e do relacionamento como um todo; a satisfação como causa e garantia para a qualidade da interação; o compromisso, que vai indicar o investimento de cada um para que a relação continue e tenha qualidade; e, ainda, a importância das características individuais e as influências sociais, numa relação dinâmica e dialética, influenciando e sendo influenciado por outros relacionamentos, sejam de amizade, sejam outras relações interpessoais. A dialética entre pessoas, estrutura sociocultural e ambiente físico mostrou-se um elemento importante para o desenvolvimento desta pesquisa, partindo-se do pressuposto de que a entrada na universidade representa a inserção em um novo ambiente sociocultural, afetando as relações das mulheres na meia-idade. Para compreender esses vínculos, é necessário considerar os comportamentos e as expectativas dessas graduandas, bem como o conteúdo e a qualidade de suas interações.

\section{OBJETIVOS E JUSTIFICATIVA}

$\mathrm{O}$ relacionamento interpessoal de mulheres em idade adulta intermediária ou meia-idade é ainda um tema de investigação recente. Pouco se sabe acerca dos encontros e desencontros que permeiam suas relações de amizade dentro de sua trajetória de vida, principalmente quando elas vencem as limitações da idade e reingressam na universidade nessa faixa etária. Há uma hipótese de que essa inovação em suas vidas traga alterações em suas relações de amizade.

Assim sendo, o objetivo desta pesquisa foi investigar as mudanças percebidas nas relações de amizade por mulheres de meia-idade, casadas e com filhos, após a sua inserção em um curso de graduação . Os objetivos específicos focaram: as mudanças percebidas no relacionamento com amigos antigos e o estabelecimento de novas amizades a partir da sua entrada na universidade; as diferenças entre as amizades antigas e as novas relações; e a interação do novo grupo com os familiares da estudante na meiaidade.

A escolha de mulheres casadas e com filhos se justifica pela responsabilidade que apresentam com uma vida familiar, de modo que retornar à universidade seria um desafio em face dos compromissos já assumidos com o ambiente familiar. $\mathrm{O}$ método aplicado foi a análise de conteúdo (Bardin, 2011). Segundo essa autora, sua principal função é o desvendar crítico. Ela não é apenas descritiva, pois usa a inferência, por meio de análises, procurando esclarecer as causas da mensagem ou as suas consequências. Essa técnica se presta a uma descrição objetiva e sistemática do conteúdo presente nas comunicações e sua interpretação.

\section{MÉTODO}

\section{Participantes}

Dada a escassez de mulheres na meia-idade frequentando a Universidade Federal do Espírito Santo (Ufes), participaram da pesquisa oito mulheres com idade entre 40 e 60 anos, graduandas de cursos distintos e que se matricularam entre 2007 e 2009 . As mulheres escolhidas deveriam ser casadas, ter filhos e estar na graduação há mais de um ano. Para que a identidade delas fosse preservada, foram usados nomes fictícios para designar a fala de cada mulher. $\mathrm{O}$ projeto foi 
aprovado pelo Comitê de Ética do Programa de Pósgraduação em Psicologia da Ufes. As participantes foram informadas do conteúdo da pesquisa e, para participarem dela, preencheram o Termo de Consentimento Livre e Esclarecido.

$\mathrm{Na}$ tabela 1 está um resumo dos dados referentes a Tabela 1 idade, graduação, período cursado, tempo em que a estudante ficou fora da escola e sua profissão atual. Todos as participantes eram casadas, tinham filhos e moravam com a família.

\section{Instrumentos}

Os dados da pesquisa foram obtidos por meio de

Dados pessoais das participantes

\begin{tabular}{lccccc}
\hline Participante & Idade & Curso & Período & $\begin{array}{c}\text { Tempo fora } \\
\text { da escola }\end{array}$ & Profissão atual \\
\hline 1- Nanci & 60 & Serviço Social & $4^{\circ}$ & 32 anos & Do lar \\
2- Lúcia & 56 & Serviço Social & $3^{\circ}$ & 31 anos & Do lar \\
3- lêda & 49 & Serviço Social & $4^{\circ}$ & 29 anos & Do lar \\
4- Ester & 44 & Serviço Social & $4^{\circ}$ & 15 anos & Do lar \\
5- Ana & 41 & Serviço Social & $4^{\circ}$ & 19 anos & Do lar \\
6- Eni & 50 & Psicologia & $6^{\circ}$ & 22 anos & Funcionária Pública \\
7- Odila & 40 & Psicologia & $6^{\circ}$ & 19 anos & Secretária \\
8- Sônia & 41 & Letras & $3^{\circ}$ & 17 anos & Professora \\
\hline
\end{tabular}

entrevista semiestruturada, individual, combinando perguntas fechadas e abertas, com o objetivo de possibilitar ao participante a oportunidade de se pronunciar sobre a temática em questão. A entrevista visou obter informações acerca das mudanças percebidas nas relações de amizade em mulheres de meia-idade inseridas em um curso de graduação da Ufes há mais de um ano. Foram abordados os seguintes pontos principais: identificação dos novos relacionamentos estabelecidos (novas amizades) e suas características e identificação das mudanças percebidas nos relacionamentos de amizade anteriores. Os dados obtidos permitiram comparar os relacionamentos interpessoais antes e após a inserção nesse novo grupo. São exemplos de questões: Fez novas amizades aqui? Como descreveria essas amizades? Como elas se diferenciam das amizades anteriores à sua entrada aqui?

\section{Procedimentos}

Foi feito um contato prévio com uma aluna de Serviço Social e ela indicou algumas colegas de outros períodos. Foram contatadas, a princípio, sete mulheres para ser entrevistadas, porém apenas cinco compareceram ao encontro. Outras cinco, dentro dessa faixa etária, foram indicadas por alunos dos cursos de Psicologia e de Letras, tendo comparecido três delas para a entrevista. Foi esclarecido a cada participante o objetivo desta pesquisa e apresentado o termo de consentimento para que assinassem, permitindo a efetivação desta investigação. As participantes foram entrevistadas individualmente, dentro de um clima de estímulo e aceitação mútua com a pesquisadora, em horário e local escolhidos por elas. Os encontros se deram nas dependências da Ufes, nos intervalos das aulas dessas mulheres. Os dados foram gravados e transcritos na íntegra e passaram por tratamento e organização. Após isso, as categorias de análise foram estabelecidas de acordo com suas similaridades, utilizando a técnica de análise de conteúdo, a partir de Bardin (2011).

\section{RESULTADOS}

Para uma melhor compreensão dos relatos obtidos e maior visualização das características singulares das participantes, os dados foram agrupados e divididos em cinco tópicos de acordo com categorias preestabelecidas, mantendo uma inter-relação entre as questões levantadas, sem perder de vista o objetivo da pesquisa. São eles: 1) relacionamento interpessoal na universidade (refere-se aos relacionamentos em geral vividos na universidade); 2) construção e propriedades das novas amizades (formação de novas amizades e suas características); 3) atividades com os novos amigos (atividades compartilhadas com os novos amigos da universidade); 4) distinção entre amizades 
antigas e amizades recentes (comparação entre as amizades anteriores à entrada na universidade e as amizades feitas na universidade); e, 5) mudanças na rotina com amigos antigos (mudanças percebidas nas amizades anteriores à entrada na universidade).

\section{Relacionamento interpessoal na universidade}

As estudantes na meia-idade tiveram um bom relacionamento no novo grupo em que se inseriram, dentro do espaço acadêmico. Para Nanci, no início houve dificuldade de interação com os mais jovens, mas hoje ela assegura:

"Eu me relaciono muito bem com as pessoas aqui. Eu procuro me inserir no contexto delas... Eu procuro não criticar e observar a atitude dos jovens".

Para Ieda, o fato de ter filhos na idade dos colegas permitiu conviver melhor com eles. Já as mulheres que trabalham fora de casa alegaram possuir um bom relacionamento pelo fato de terem contato com muitas pessoas fora desse ambiente. Apenas Ana diz sentir dificuldade em se relacionar com os colegas mais novos, apontando preconceito e discriminação por parte deles:

"Eu vejo muito preconceito dentro da Ufes, em relação à cor, à idade, ao estilo... Se eu não venho bem vestida eles olham de forma diferente $[\ldots] "$.

\section{Construção e propriedades das novas amizades}

Todas as participantes construíram novos relacionamentos no meio acadêmico. Eni, embora satisfeita com as novas relações, deixou evidente que estabeleceu relações de coleguismo e não de amizade, no novo grupo universitário. Como sua filha estuda no mesmo curso que ela, Eni enfatiza:

“[...] Aqui, eu não posso considerar essa turma como amigas. Elas são apenas colegas, talvez amigas de minha filha, que é da idade delas".

As propriedades das novas amizades se apresentam de forma diferenciada para as mulheres. Para Ester, as amizades não se restringiram aos colegas da graduação, mas se estenderam a pessoas de idades e cursos variados dentro das dependências da Ufes. Para algumas estudantes, as novas amizades aconteceram entre as alunas que estão dentro da mesma faixa etária que elas. Para Ieda, esse atributo é uma garantia de manutenção e conservação do relacionamento de amizade para além dos portões da universidade:

"Eu fiz amizades aqui, com o grupo da minha faixa etária, que eu sei que vou levar quando sair daqui”.
Elas se mostram muito satisfeitas com as amizades recentes, mas essa relação não se estende aos familiares da maioria das participantes. A distância entre suas residências, o pouco tempo disponível e as singularidades de cada família impedem uma maior aproximação entre os maridos e filhos dessas mulheres com seu novo grupo de convivência dentro da Ufes. Apenas Odília, a participante mais nova, conseguiu uma maior interação entre sua família e os novos amigos universitários.

O distanciamento entre os familiares e os novos amigos universitários das participantes não implica que o mesmo ocorra entre elas. Foram observadas satisfação e intimidade quando falam das novas amigas, com quem querem estar na maior parte do dia. A cumplicidade está presente entre essas mulheres, que estabeleceram uma relação de amizade muito grande. Para Ana, elas se apoiam e se fortalecem:

"Juntas nós desabafamos. Hoje mesmo já chorei até no ombro amigo dela. A gente se ajuda sempre".

Elas mostraram que, dentro desse grupo de mesma faixa etária, elas enfrentam dificuldades semelhantes dentro da universidade. O prazer nas novas amizades está relacionado à identificação presente entre elas, à homogeneidade do grupo e à semelhança das dificuldades que enfrentam para estar naquele espaço acadêmico. Poder partilhar esses sentimentos e ser compreendida aumenta a parceria e a cumplicidade entre as participantes.

\section{Atividades com os novos amigos}

Os encontros com os novos amigos se dão apenas dentro das dependências da universidade, confirmando a separação entre a vida familiar e a vida acadêmica das participantes. Lúcia alegou que restringe à Ufes os encontros com as amigas e as atividades acadêmicas a serem feitas em grupo, para não aumentar ainda mais os conflitos na família, como o alcoolismo do marido e a não aceitação, pelos filhos, de sua nova condição de estudante. Nanci expressa bem sua rotina diária com as novas amigas:

"Aqui dentro nós conversamos, estudamos, andamos pela

Ufes. Tem dia que ficamos aqui o dia todo juntas".

Somente Odília mantém um vínculo mais íntimo com colegas mais novos e com aqueles da mesma faixa etária que ela, se encontrando em barzinhos, cinema e frequentando a casa deles para fazer atividades acadêmicas. 


\section{Distinção entre amizades antigas e amizades recentes}

Para Odília, não há distinção entre as novas amizades e as amizades anteriores à sua entrada na Ufes, pois ela faz os mesmos programas com os dois grupos, promovendo encontros entre os amigos recentes e os antigos. Muitas de suas amigas antigas voltaram a estudar também, o que torna os interesses muito parecidos. Nanci e outra colega diferenciam, sem qualificar, os dois grupos de amigos, convivendo bem com ambos. Nanci diz:

"Eu sou de uma denominação religiosa evangélica, mas adquiri amigos aqui que não são evangélicos. Os meus amigos fora da UFES são evangélicos. Eu sei conviver bem tanto com uns quanto com os outros".

A metade do grupo de mulheres diferenciou as amizades recentes das antigas, qualificando positivamente as novas amizades.

Para Lúcia, a universidade se torna um lugar de privacidade onde, longe do olhar da família, pode deixar cair a máscara e ser ela mesma, sem reservas, tendo a cumplicidade e o companheirismo das novas amigas, que compartilham de suas angústias e alegrias:

"Essas amizades daqui me realizam mais que as outras. Elas representam um momento só meu. As amizades fora daqui são mais superficiais".

Lúcia indica que o novo grupo possui qualidades ausentes nos amigos antigos, bem como na família, que ignora suas necessidades. Ana atribuiu "falsidade e interesse" aos amigos antigos que moram no Espírito Santo, enquanto as amizades recentes, construídas na universidade, são sinceras e verdadeiras:

"As amigas de agora, da Ufes, não tentam me agradar para ter algo em troca mais tarde, porque temos muito em comum... Os amigos da igreja, da vizinhança, para quem eu passava despercebida, hoje me tratam com a maior atenção".

Seus amigos antigos, que ficaram na Bahia, conservaram um carinho especial por ela e a consideram pessoa notável na cidade, por cursar uma graduação. Ana orgulha-se desses amigos. A maioria das mulheres reconhece que se modificou a partir dos novos conhecimentos, e hoje elas podem fazer uma análise mais crítica das relações que estabelecem e da forma como passaram a ver o mundo que as cerca. Preferem as amigas da universidade, pois elas compartilham dessa nova visão de mundo e desfrutam de um diálogo mais rico em informações e conhecimentos. Após esse tempo na universidade, Ieda já não comunga da forma de pensar e agir dos amigos do interior:

“[...] As pessoas no interior são muito simples e elas falam a verdade nua e crua. Então, muitas coisas que eu escuto agora, eu não falo nada, mas não os deixo perceber que já não penso daquela forma".

\section{Mudanças na rotina com amigos antigos}

Entre as universitárias na meia-idade, a falta de tempo disponível prejudica a manutenção das amizades antigas. $\mathrm{O}$ alto volume de leituras da graduação e a carga horária de aulas a cumprir requerem um período longo de seus dias, impedindo que se dediquem com a mesma assiduidade aos antigos compromissos com os velhos amigos. Algumas falas mostram que essas estudantes foram substituindo o convívio social por uma vida acadêmica, como aponta Lúcia:

“[...] Eu tinha muita relação com o grupo da igreja, da comunidade, com algumas famílias com quem viajávamos. Isso também mudou... Agora não dá mais tempo, só nas férias mesmo".

Ieda largou suas atividades de lazer:

“[...] Hoje eu estou mais afastada do vôlei porque o tempinho que sobra é pra eu estudar".

Para algumas estudantes, a rotina com as amizades antigas foi muito afetada, visto que renunciaram aos encontros e às atividades com os grupos dos quais faziam parte que incluíam lazer, religião, encontros sociais para cursar uma graduação que consome grande parte do seu tempo disponível. Foi observado que as novas amizades estão cada vez mais presentes na vida dessas estudantes, tornando raros os encontros com amigos antigos.

Por motivos distintos, não houve mudança na rotina com amigos antigos para as participantes restantes. " $A$ amizade antiga se apresentou muito superficial" para Ieda, assim como para outras mulheres do grupo, que são muito dedicadas à família, concedendo-lhe atenção exclusiva:

“[...] Eu sempre fui muito reservada, nunca saí muito, me restrinjo à minha família".

Para Lúcia, o contato com amigos antigos era muito pequeno devido aos conflitos enfrentados pela família:

"[...] Eu nunca levei pessoas para frequentar a minha casa justamente pelo problema da bebida do marido. Eu nunca sei quando ele está atacado e inconveniente".

Odília diminuiu os encontros com os amigos antigos, devido à falta de tempo e às atividades da graduação, mas ela preserva o hábito de saírem e jantarem juntos, não considerando, portanto, que tenha 
havido mudança na rotina com eles.

As participantes se sentem mais abertas para estabelecer novas amizades hoje. Elas vêm adquirindo uma maior compreensão da natureza humana, que o conhecimento acadêmico proporciona, como mostra Ester:

"Hoje, com mais conhecimento, eu tenho mais segurança para conversar, para interagir com outras pessoas. $\mathrm{O}$ serviço social abre muito esse campo, da alteridade".

Observam-se diminuição da timidez e aumento da autoestima, o que dá a elas mais segurança para conversar e interagir com outras pessoas.

\section{DISCUSSÃO}

A universidade, espaço de socialização e convivência, é um marco divisor de duas realidades distintas para essas estudantes. De seus muros para dentro há um mundo privado, que a graduanda na meiaidade não quer partilhar com a outra realidade vivida fora dos seus portões.

Sendo o espaço acadêmico palco de inúmeras interações, que vão formar a rede de relações das participantes desta pesquisa, é possível dizer que ele é também um campo de realizações pessoais, de construções de amizades e de aquisição do saber. Nesse sentido, as amizades estabelecidas dentro desse contexto se deram a partir das similaridades, do companheirismo e da cumplicidade entre as parceiras. Esses atributos vão fortalecer as crenças positivas no futuro do relacionamento, reduzir as possibilidades de conflitos de opiniões melhorando, assim, os resultados das atividades e provocar um aumento na satisfação com o relacionamento. Hinde (1997) assegura que características pessoais, o tipo de relacionamento e seus fatores contextuais, a natureza relacional $e$ as expectativas de cada participante colaboram para a satisfação no relacionamento. Para Rawlins (1992), a entrada no ensino superior leva à criação de uma rede de apoio social e à reavaliação do relacionamento com a família e com as amizades preexistentes em adultos jovens, sendo a fase estudantil universitária favorável à formação de grandes amizades. Portanto, os dados sugerem que as relações de amizade da mulher de meia-idade também podem ser afetadas pela entrada na universidade.

Apesar de a literatura indicar que, na fase adulta intermediária, há um número menor de amigos em detrimento da família e da carreira (Sousa \& CerqueiraSantos, 2011) e de a rede de amizades de adultos de meia-idade se apresentar centrada na família e menor que a de adultos jovens (Nogueira, 2001), isso não impede que novas amizades sejam construídas, no ambiente universitário, pelas mulheres de meia idade, conforme observado no presente estudo.

Como indicado por outros autores, para jovens adultos (Peron, Guimarães, \& Souza, 2010) e para idosos (Garcia \& Leonel, 2007; Webber \& Celich, 2007), com a entrada na universidade, houve mudanças nos relacionamentos de amizade em relação às mulheres de meia-idade que participaram do presente estudo. E, como observado por Irigaray e Schneider (2008) no caso de idosos na universidade, há mudanças na autoestima e um novo sentido de vida, o que também foi observado nesta investigação. Contudo, as alterações notadas na vida social do idoso parecem ser mais positivas e menos conflituosas que as mudanças percebidas na vida das mulheres de meia-idade que passam a frequentar a universidade. Hutz e Souza (2008) também assinalam que a solidão é abrandada pela construção da amizade.

Os resultados obtidos neste trabalho são similares aos alcançados por Toneloto (1998) em relação à vida social de estudantes de meia-idade no meio universitário, no sentido de que frequentar a universidade traz uma ressignificação ao cotidiano dessas mulheres, em função também de novos relacionamentos. Raposo (2006) reconheceu que a qualidade de vida de quem ingressa na universidade após 45 anos apresentou melhorias, destacando-se o aspecto pessoal, seguido do familiar, do trabalho, social e financeiro. Os resultados da presente pesquisa indicam uma situação mais ambígua. As mudanças relacionadas às amizades foram mais diversificadas que as observadas pela autora, que não identificou mudanças em termos do círculo de amizades a partir da relação com os colegas da universidade. Leão e Gíglio (2002), em outro contexto da vida da mulher de meiaidade, apontaram as atuais exigências ambientais, desejo de progresso, integração e produtividade social, o que é coerente com a busca do ensino superior.

Em relação às transformações da mulher na meiaidade, segundo Jorge (2005), os relacionamentos e os vínculos mudam na maturidade, tanto no sentido de um estreitamento das relações quanto no de um distanciamento. $\mathrm{O}$ afastamento e o distanciamento também foram notados no atual estudo, tendo-se que levar em consideração o contexto social das universitárias na meia-idade. A diversidade encontrada 
nas relações sociais está de acordo com a observação de Silva e Souza (2006), para quem a meia-idade é uma fase experienciada de maneira individualizada, que vai depender do modelo de vida e do contexto social em que está inserida. A dificuldade em administrar o tempo e em lidar com o preconceito e com o estresse, bem como com a falta de apoio da família, é um desafio enfrentado por algumas participantes nessa jornada universitária.

Apesar de a literatura sobre mulher na universidade tradicionalmente tratar do acesso feminino ao ensino superior (Baldissera, Grecca, \& Santos, 2010; Reis \& Brito, 2012), a participação da mulher de meia-idade representa um novo desafio, não somente em função do gênero, mas também em função da idade, inclusive para a construção de novas amizades.

Esse grupo de mulheres enfrentou desafios e passou por muitas mudanças em suas vidas e, consequentemente, em seus relacionamentos para estar hoje cursando uma graduação na universidade. Essas transformações ocorreram como um processo dialético, de acordo com suas inter-relações, considerando os fatores ambientais e socioculturais, promovendo, assim, uma inovação em seus conceitos a partir do conhecimento alcançado. As situações vividas geraram, em alguns casos, momentos de conflitos, considerados construtivos quando acompanhados pelo prazer do conhecimento novo que a universidade traz. Porém, de acordo com os conceitos de Hinde (1997), os conflitos também podem se apresentar de forma destrutiva, provocando desgastes nas relações. Isso acontece com algumas participantes do grupo, que não conseguem administrar as cobranças dos amigos antigos quando o excesso de atividades acadêmicas lhes rouba o tempo de se dedicarem a eles. A natureza construtiva ou destrutiva do conflito vai depender de como a mulher enfrenta as dificuldades vividas na meia-idade.

\section{CONSIDERAÇÕES FINAIS}

A dificuldade em administrar o tempo e em lidar com o preconceito e com o estresse, bem como com a falta de apoio de amigos e familiares, é um desafio enfrentado pelas participantes desta pesquisa nessa jornada universitária. Elas vão, aos poucos, superando e vencendo os obstáculos à medida que interagem com novos grupos e são influenciadas pelas pressões socioculturais que configuram a dinâmica de seus relacionamentos. A vontade de se atualizar, fugir da solidão ou realizar um sonho é um fator que reflete a preocupação de buscarem envolvimento com diferentes pessoas, com outras atividades, construindo novas amizades e enfatizando a importância de novos projetos de vida. Os novos papéis desempenhados pela mulher na meia-idade, como estudante universitária, provocam uma diversidade de situações, com resultados singulares, apontando alterações nas suas relações interpessoais.

Embora os resultados deste estudo contribuam com uma lacuna de conhecimento sobre as mulheres de meia-idade inseridas na universidade, convém destacar algumas limitações, como o pequeno número de participantes, as dificuldades para o acesso a possíveis participantes por se tratar de um grupo ainda reduzido nas universidades, a seleção de participantes por conveniência, o caráter mais descritivo do estudo e o fato de as categorias da análise de conteúdo não terem sido avaliadas por juízes. Os dados também sugerem a possibilidade de uma maior atenção das universidades para a diversidade de seus estudantes e suas necessidades sociais, como é o caso dos alunos de meia-idade.

\section{REFERÊNCIAS}

Baldissera, R. S., Grecca, F. S., \& Santos, R. B. (2010). Participação das mulheres na graduação da Faculdade de Odontologia da Universidade Federal do Rio Grande do Sul. Rev Fac Odontol Porto Alegre, 51(1), 27-30.

Barbosa, C.G., Melchiori, L.E. \& Neme, C.M.B. (2011). O significado da morte para adolescentes, adultos e idosos. Paidéia (Ribeirão Preto), 21 (49), 175-185.

Bardin, L. (2011). Análise de conteúdo. 4. Ed. Trad. Luís Antero Reto, Augusto pinheiro. São Paulo: Edições 70.

Bowman, N. A., \& Park, J. J. (2014). Interracial contact on college campuses: Comparing and contrasting predictors of cross-racial interaction and interracial friendship. The Journal of Higher Education, 85(5), 660-690.

Charles, S. F. (2012). The Effect of Extracurricular Activities on Friendship Diversity: A Look into an Organizational Aspect of College Activities and Cross-Group Relationships. Colgate Academic Review, 9 (1), 195-203.

Ferreira, M.E.M.P. (2008). A meia idade e a alta modernidade. Construção psicopedagógica, 16 (13), 7791.

Garcia, A. \& Brandão, L.R. (2010). Amizade e focos de atividade na universidade. Interpersona, 4 (2), 318-345.

Garcia, A. (2005). Psicologia da Amizade na Infância: Uma Revisão Crítica da Literatura. Interação em Psicologia, 9 (2), 285-294.

Garcia, A., \& Leonel, S. B. (2007). Relacionamento interpessoal e terceira idade: a mudança percebida nos relacionamentos com a participação em programas sociais para a terceira idade. Pesquisas e Práticas Psicossociais, 2 (1), 130-39. 
Giolo, J. \& Ristoff, D. (2006). Trajetória da mulher na educação superior brasileira. Brasília: Instituto Nacional de Estudos e Pesquisas Educacionais Anísio Teixeira.

Guimarães, A.C.A. \& Baptista, F. (2013). Prevalence of sufficient physical activity in middle-aged women from a Brazilian state capital. Revista Brasileira de Cineantropoetria e Desempenho Humano, 15 (6), 677685.

Hinde, R. A. (1997). Relationships: a dialectical perspective. London: Psychology

Hutz, C. S., \& Souza, L. K. (2008) Relacionamentos pessoais e sociais: amizades em adultos. Psicologia em Estudo, Maringá, 13 (2), 257-265.

IBGE - Instituto Brasileiro de Geografia e Estatística (2011). Acesso em 31 de outubro, 2011, de http://www.censo2010.ibge.gov.br/sinopse/webservice/

Irigaray, T. Q., \& Schneider, R. H. (2008). Impacto na qualidade de vida e no estado depressivo de idosas participantes de uma universidade da terceira idade. Estudos de Psicologia (Campinas), 25 (4), 517-525.

Jorge, M. M. (2005). Perdas e ganhos do envelhecimento da mulher. Psicologia em Revista, 11 (17), 47-61.

Kim, Y. K., Park, J. J., \& Koo, K. K. (2014). Testing SelfSegregation: Multiple-Group Structural Modeling of College Students' Interracial Friendship by Race. Research in Higher Education, 1-21.

Leão, M.A.B.G. \& Gíglio, J.S. (2002). Psicodinâmica da mulher trabalhadora de meia-idade em fase de préaposentadoria. PsicoUSF, 7(2), 185-194

Marcelja, K. G. (2012). Quem é Barbara? A envelhescência na mídia impressa feminina brasileira. Revista Brasileira de Ciências do Envelhecimento Humano, 7 (Supl. 1), 112-123, 2010

Merighi, M. A. B., Jesus, M. C. P., Domingos, S. R. F., Oliveira, D. M., \& Baptista, P. C. P. (2011). Ser docente de enfermagem, mulher e mãe: desvelando a vivência sob a luz da fenomenologia social. Revista Latino-Americana de Enfermagem, 19(1), 164-70.

Nogueira, E.J. (2001) Rede de relações sociais: Um estudo transversal com homens e mulheres pertencentes a três grupos etários. Tese de doutorado, Faculdade de Educação, Universidade Estadual de Campinas, SP, Brasil.

Papalia, D. E \& Olds, S. W. (2000). Desenvolvimento Humano. ( $7^{\mathrm{a}}$ ed.). Porto Alegre: Artes Médicas Sul.

Peron, S. I., Guimarães, L. S., \& Souza, L. K. (2010). Amizade na adolescência e a entrada na universidade. Estudos e Pesquisas em Psicologia, 10 (3), 664-681.
Pureza, J.R., Rusch, S.G.S., Wagner, M. \& Oliveira, M.S. (2012). Treinamento de habilidades sociais em universitários: uma proposta de intervenção. Revista Brasileira de Terapias Cognitivas, 8(1), 2-9.

Raposo, D.M.S.P. (2006) A qualidade de vida de estudantes que ingressam na universidade na meia-idade. Revista Brasileira de Estudos Pedagógicos, 87 (217), 370-381.

Rawlins, W. (1992). Friendship matters. New York: Aldine de Gruyter.

Reis, L.M. \& Brito, M.G. (2012). Curso de "Artes Práticas: Educação para o Lar" da Universidade Católica de Minas Gerais: rupturas e permanências na relação mulher, família e ensino na década de 1970. Cadernos de História, 13 (18), 64-78.

Silva, C, A. \& Souza, S. V de (2006). O significado da chegada da meia-idade na perspectiva de um grupo de mulheres. Revista de Iniciação Científica, 4 (1), 101-111.

Simoneau, A. \& Oliveira, D.C. (2011). Programa universitário para pessoas idosas: a estrutura da representação social. Arquivos Brasileiros de Psicologia, 63(1), 11-21.

Sousa, D.A. \& Cerqueira-Santos, E. (2011). Redes sociais e relacionamentos de amizade ao longo do ciclo vital. Revista Psicopedagogia, 28 (85), 53-66.

Souza, L. K. \& Garcia, A. (2008). Amizade em Idosos: Um panorama da produção científica recente em periódicos estrangeiros. Estudos Interdisciplinares sobre o Envelhecimento, 13, 173-190.

Toneloto, V. A. F. S. (1998). Mulheres de Meia-Idade que frequentam a universidade. Dissertação de mestrado, Faculdade de Educação, Universidade Estadual de Campinas, Campinas, SP, Brasil.

Wang, J. L., Jackson, L. A., Gaskin, J., \& Wang, H. Z. (2014). The effects of Social Networking Site (SNS) use on college students' friendship and well-being. Computers in Human Behavior, 37, 229-236.

Webber, F. \& Celich, K.L.S. (2007). As contribuições da universidade aberta para a terceira idade no envelhecimento saudável. Estudos Interdisciplinares sobre o Envelhecimento, 12, 127-142.

Notas:

${ }^{1}$ Mestre em Psicologia pela UFES

${ }^{2}$ Doutor em Psicologia pela USP, Professor do Departamento de Psicologia Social e do Desenvolvimento e do Programa de Pós-Graduação em Psicologia da UFES. Bolsista de Produtividade em Pesquisa do CNPq. 